\title{
GENDER DIFFERENCES IN HEALTH: A CANADIAN STUDY OF THE PSYCHO-SOCIAL, STRUCTURAL AND BEHAVIOURAL DETERMINANTS OF HEALTH
}

\author{
Margaret Denton ${ }^{1}$, Steven Prus ${ }^{2}$ and Vivienne Walters ${ }^{3}$
}

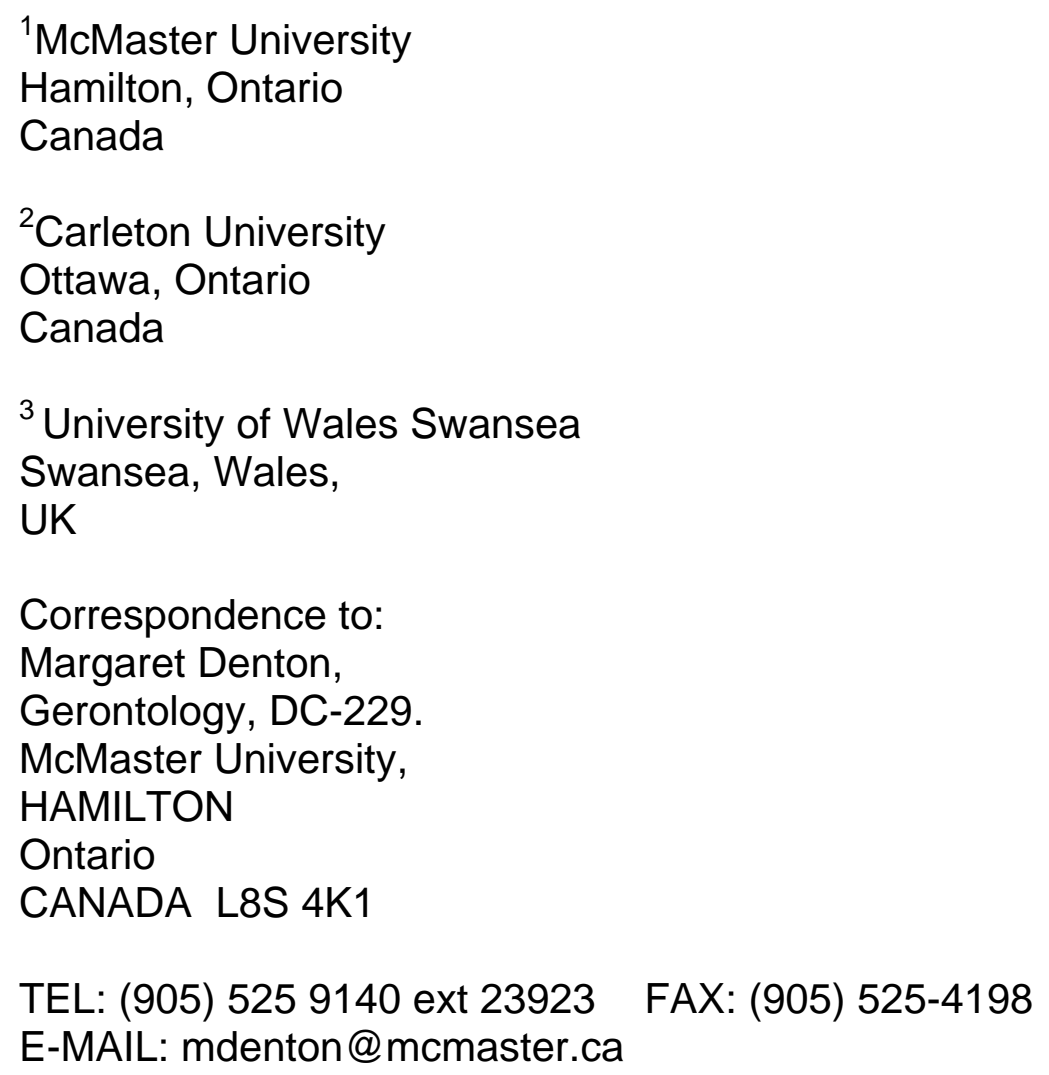


GENDER DIFFERENCES IN HEALTH:

A CANADIAN STUDY OF THE

PSYCHO-SOCIAL, STRUCTURAL AND

BEHAVIOURAL DETERMINANTS OF HEALTH

SHORT TITLE:

GENDER DIFFERENCES IN HEALTH

KEY WORDS: GENDER; DETERMINANTS OF HEALTH; INEQUALITIES IN HEALTH; CANADA. 


\begin{abstract}
Gender-based inequalities in health have been documented. This paper examines the extent to which these inequalities reflect the different social experiences and conditions of men's and women's lives. We address four specific questions. Are there gender differences in mental and physical health? What is the relative importance of the structural, behavioural and psycho-social determinants of health? Are the gender differences in health attributable to the differing structural (socio-economic, age, social support, family arrangement) context in which women and men live and to their differential exposure to lifestyle (smoking, drinking, exercise, diet) and psycho-social (critical life events, stress, psychological resources) factors? Are gender differences in health also attributable to gender differences in vulnerability to these structural, behavioural and psycho-social determinants of health?

Multivariate analyses of Canadian National Population Health Survey data reveal significant gender differences in health, measured by self-rated health, functional health, chronic illness and distress. Second, these analyses demonstrate that for both men and women, structural determinants of health as a group explain the greatest proportion of the variance in self-rated, functional and chronic health, while psycho-social determinants as a group are the strongest predictors of distress. Third, they show that gender differences in exposure to these forces somewhat contribute to inequalities in health between men and women, however, statistically significant inequalities generally remain after controlling for exposure. Fourth, the analyses reveal that gender-based health inequalities are further explained by differential vulnerabilities to social forces between men and women.
\end{abstract}

Our findings suggest the value of models which include a wide range of health and healthdeterminant variables, and affirm the importance of looking more closely at gender differences in health. 


\section{Introduction}

\section{LITERATURE REVIEW}

This paper builds on the contribution of our own work (and the work of our coauthors) to the understanding of the social structural and behavioural determinants of health (Denton \& Walters, 1999; Walters, McDonough \& Strohschein, 2002; McDonough, 2000; McDonough \& Walters, 2002) and the psycho-social determinants of health (McDonough, Walters \& Stroschein, 2002). It adds to this literature by assessing the relative contribution to health of these three categories and by evaluating two explanations of gender differences, namely that men and women are differentially exposed to these determinants of health or that they are differentially vulnerable to these determinants. Further, to gain a comprehensive understanding of the role that such factors play in determining health, we use multiple indicators of both physical and mental health. In this section we provide an overview of the theoretical and empirical literature on the social explanations of inequalities in health between men and women.

\section{Gender Inequalities in Health}

While women generally experience poorer health than men, the pattern of gender differences in health is varied (Arber \& Cooper, 1999; Macintyre, Hunt \& Sweeting, 1996; also see the special issue of Social Science and Medicine edited by Hunt \& Annandale, 1999). Women have lower rates of mortality but, paradoxically, report higher levels of depression, psychiatric disorders, distress, and a variety of chronic illnesses than men (Baum \& Grunberg, 1991; McDonough \& Walters, 2001; Verbrugge, 1985). However, the 
direction and magnitude of gender differences in health vary according to the symptom/condition and phase of the life cycle. Female excess is found consistently across the life span for distress, but is far less apparent, even reversed, for a number of physical symptoms and conditions (Macintyre, Hunt \& Sweeting, 1996; Matthews, Manor \& Power, 1999).

\section{Social Explanations of Inequalities in Health}

The roots of health inequalities are many, interconnected and complex. In addition to health inequalities being linked to genetic and biological differences, social variables have been identified as a source of health inequalities, which are generally grouped into three categories: social structural, behavioural and psycho-social factors.

In terms of structures of social inequality, research has documented a relationship between health inequalities and socio-economic inequalities in income, education, occupational status and employment status (Arber, 1997; Blaxter, 1990; D'Arcy 1998; Denton \& Walters, 1999; Marmot, 1997; Townsend \& Davidson, 1982; Walters, Lenton \& McKeary, 1995). Studies also find that health status is a function of other social structural factors such as social support (Blaxter, 1990; House, Landis \& Umberson, 1994; Kessler \& McLeod, 1985), marital status (Walters, McDonough \& Stroschein, 2002), age (Arber \& Cooper, 1999; Walters, Lenton \& McKeary, 1995) and as described above gender.

Lifestyle behaviours (e.g., tobacco and alcohol consumption, exercise and diet) are also linked to health and illness (Blaxter, 1990; Denton \& Walters, 1999; Lantz, Lynch, House, Lepkowshi, Mero, Muscik et al., 2001). A healthy lifestyle can help prevent, for 
example, weight gain, high blood pressure, diabetes, arthritis, stress, and early mortality. A more complete discussion of social structural and behavioural determinants of health can be found in our previous work (Denton \& Walters, 1999) on gender inequalities in health. Here, we turn our attention to a more detailed discussion of the psycho-social determinants.

In contrast to social structural factors, psycho-social determinants of health occur at the individual, subjective level. We categorize them into three groups, which are interrelated: critical life events, chronic stressors and psychological resources.

First, numerous research studies show that people exposed to stressful life events are at greater risk of psychological distress and psychiatric disorders (Kessler, Price \& Wortman, 1985), poor physical health (Jemmot \& Locke, 1984) and substance abuse (Turner \& Lloyd, 1995). Second, while much of the research on the impact of stress on health has focussed on exposure to life events, others point to the role of chronic stressors (i.e., the ongoing and difficult conditions of daily life) (McDonough \& Walters, 2001; McDonough, Walters, \& Strohschein, 2002; Pearlin, 1989; Wheaton, 1994). McDonough and Walters (2001) found that exposure to social life stress, financial stress, relationship stress, child (i.e., parenting-related) stress, environmental stress, family health stress and job strain were all positively associated with distress and, to a lesser extent, chronic health conditions. Third, among psychological determinants of health, self-esteem, sense of coherence (SOC) and mastery are well-documented determinants of health. They work directly through their positive associations with higher levels of health and indirectly by 
modifying the effects of chronic stressors or the impact of stressful life events on health (Pearlin, Lieberman, Menaghan \& Mullan, 1981).

Specifically, self-esteem refers to the positiveness of one's attitude towards oneself (Pearlin \& Schooler, 1978, p.5), and low self-esteem has been linked to higher levels of depression (Rosenberg, Schooler \& Schoenbach, 1989) and lower levels of self-rated health (McDonough, 2000). SOC is a coping resource that facilitates successful coping with the stressors of life. Antonovsky states that the hallmark of the strong-SOC person is the ability, in confronting a stressful life situation, to choose what seems to be the most appropriate strategy from among the variety of potential resources available (1987, p140). Persons high in SOC tend to perceive demands/stress as challenges worthy of engagement rather than as threats or stressors. Numerous studies document relationships between SOC and mental and physical health (see Kivimaki, Feldt, Vahtera \& Nurmi, 2000). In terms of mastery or the extent to which one regards one's life chances as being under one's own control in contrast to being fatalistically ruled (Pearlin \& Schooler, 1978, p.5), research studies show that it is associated with lower levels of depression, better selfrated health, longevity, and lower levels of activity limitations and psycho-social symptoms (McDonough, 2000; Mirowshy \& Ross, 1989). McDonough (2000) also finds that high selfesteem and mastery modify the effects of job stress on distress.

It is important to note that psycho-social, as well as behavioural, forces do not exist within a vacuum; that is, lifestyle behaviours, exposure to stressful life events, the experience of chronic stress and the level of psychological resources are rooted in the 
social structural context of people's lives. For example, the prevalence of most health-risk behaviours is higher among those within lower social classes (Blaxter, 1990; Denton \& Walters, 1999; Lantz et al., 2001). Further, the experiences of stressful life events and chronic stressors in everyday life are also socially patterned by socio-economic status, as well as by age, social support, marital status, and the presence of children in the home (Pearlin, 1989; Turner \& Lloyd, 1995; Zuzanek \& Mannell, 1998). The literature on social support, for instance, has clearly demonstrated a direct association with better mental and physical health; yet, social support also works indirectly by buffering the health-damaging effects of negative life events and chronic strains (Blaxter, 1990; House, Landis \& Umberson, 1994; Kessler \& McLeod, 1985).

It is additionally important to note that lifestyle and psycho-social experiences of individuals are also patterned by gender. This is the focus of the following discussion.

\section{Social Explanations of Inequalities in Health: A Gender Divide}

Since gender is a measure of both biological/genetic and social differences, it is likely that the health inequalities between men and women discussed earlier reflect both sex-related biological and social factors, and the interplay between them (Bird \& Rieker, 1999; Verbrugge, 1989). In terms of social factors, researchers pose two general hypotheses to account for gender-based inequalities in health. The differential exposure hypothesis suggests that women report higher levels of health problems because of their reduced access to the material and social conditions of life that foster health (Arber, 1999; Ross \& Bird, 1994) and from the greater stress associated with their gender and marital 
roles. The differential vulnerability hypothesis, on the other hand, suggests that women report higher levels of health problems because they react differently than men to the material, behavioural and psycho-social conditions that foster health (McDonough \& Walters, 2001; Turner \& Avison, 1987).

Differential exposure hypothesis Research shows that women occupy different structural locations than men: they are less likely to be employed, work in different occupations, more likely to have lower incomes and to do domestic labour and to be a single parent than men (Denton \& Walters, 1999; Ross \& Bird, 1994). There are also gender differences in exposure to various lifestyle behaviours, with men more likely than women to smoke, consume alcohol, have an unbalanced diet and to be overweight, while women are more likely than men to be physically inactive (Denton \& Walters, 1999; Ross \& Bird, 1994; Uitenbroek, Kerekovska \& Feitchieva, 1996). Evidence also suggests that women report higher levels of health problems because they are exposed to higher levels of demands and obligations in their social roles, as well as experiencing more stressful life events (de Vries \& Watt, 1996; Turner \& Avison, 1987). There are also important gender differences in perceived control and in self-esteem, with women reporting lower levels of both resources than men (Mirowsky \& Ross, 1989; Turner \& Roszell, 1994); although women do report higher levels of social support (Umberson, Chen, Hopkins \& Slaten, 1996). Research using mulitivariate analysis shows that when differential exposure to the structural, behavioural and psycho-social determinants of health are used as mediators between gender and health, gender differences in health are only partly explained 
(McDonough \& Walters, 2001; Roxburgh, 1996; Walters, McDonough \& Strohschein, 2002).

Differential vulnerability hypothesis Multivariate analyses, in which gender differences in the influence of predictors of health are examined, also show that men and women differ in vulnerability to some, but not all, of the social determinants of health. That is, the moderating effect of gender is determinant-specific. Specifically, high income, working fulltime and caring for a family and having social support are more important predictors of good health for women than men (Denton \& Walters, 1999; Prus \& Gee, 2003; Shye, Mullooly, Freeborn \& Pope, 1995). Smoking and alcohol consumption are more important determinants of health status for men than women, while body weight and being physically inactive are more important for women (Denton \& Walters, 1999). Moreover the effects of stress may be experienced and embodied by women and men in different ways. The literature shows that women react more to ongoing strains than men do. For example, women are more likely to report and react to stressors experienced by others, especially their spouse (Turner \& Avison, 1987), and men are more likely to mention and react to economic stressors (Kessler \& McLeod, 1984; Wheaton, 1990). McDonough, Walters \& Strohschein (2002) found social life stress, child (parental) stress, environmental stress and family health stress to be linked to long-standing health conditions for women but not for men. Some researchers argue that women have greater vulnerability to the effects of such chronic stressors on health due to the greater stress associated with their family and marital roles (Zuzanek \& Mannell, 1998). 
By contrast, studies have not shown gender differences in the association between the number of stressful life events and health (McDonough, 2000; Turner \& Lloyd, 1995). And while research has shown that women are more likely to hold jobs with lower levels of substantive complexity and control over tasks (Pugliesi, 1995; Roxburgh, 1996), there is little evidence that women are more vulnerable to job strain (Roxburgh, 1996). Research is also unclear on gender differences in vulnerability to psychological resources for health. However, there is some evidence that SOC plays a more pronounced role in women's health than men's (Kivimaki et al., 2000). As discussed next, this paper adds to this literature, and helps to identify gender differences in vulnerability and exposure to specific psycho-social, as well as social structural and behavioural, determinants of health.

\section{Research Question}

We have argued that levels of health are determined by social structures of inequality, differences in health-related behaviours and psycho-social factors including stressful life events, chronic stressors and psychological resources. But the picture is much more complex than that. Life style and psycho-social factors are rooted in the social structures of inequality that define people's lives, such as gender.

In the previous section, we presented various findings from the literature to argue that women are in poorer health than men partly because of their relative lack of material resources and their greater exposure to life stresses (i.e., differential exposure hypothesis). Gender differences in health also exist because the effects of social structural, behavioural and psycho-social forces are embodied by women and men in different ways (i.e., 
differential vulnerability hypothesis). This paper examines the extent to which these inequalities reflect the different social experiences and conditions of men's and women's lives. We address four specific questions. Are there gender differences in mental and physical health? What is the relative importance of the structural, behavioural and psychosocial determinants of health? Are the gender differences in health attributable to the differing structural (socio-economic, age, social support, family arrangement) context in which women and men live and to their differential exposure to lifestyle (smoking, drinking, exercise, diet) and psycho-social (critical life events, stress, psychological resources) factors? Are gender differences in health also attributable to gender differences in vulnerability to these structural, behavioural and psycho-social determinants of health?

The paper also adds a unique contribution to this literature. Specifically, many research studies focus on one or two measures of health, and in so doing may overestimate or underestimate the importance of various determinants in predicting health problems. To gain a comprehensive understanding of the role that social factors play in determining health, we use multiple indicators of health and its social structural, behavioural and psycho-social determinants. This provides insight into, for example, whether or not gender differences in the exposure and vulnerability to the social determinants of health occur in a uniform (i.e., the same determinants operate in a similar fashion across all aspects/measures of health) or in a health-specific manner.

\section{METHODS}




\section{Data}

Data from the Canadian National Population Health Survey (NPHS) are used for this analysis. Based on a multi-stage stratified probability sampling design developed by Statistics Canada, the NPHS collects information from private household residents on health and illness, use of health services, determinants of health, and demographic and economic characteristics of individuals. While the NPHS produces data for both crosssectional and longitudinal purposes, this study is based on the 1994-1995 (i.e., Cycle 1) cross-sectional component of the NPHS because it is the only NPHS survey to date that included complete information on psycho-social resources, critical life events and chronic stressors.

While data were collected from all sampled household members, one person over 12 years of age in each household was randomly selected for a more in-depth interview (i.e., the general portion of the 1994-1995 NPHS questionnaire was administered on approximately 60,000 respondents, and about 18,000 answered the more detailed health portion) - the findings presented here are based on these in-depth interviews. The selected-person response rate was about $96 \%$. The original sample weights take into consideration sampling design and population representation, but are re-scaled in this analysis so that the average weight is equal to one (i.e., survey weights are re-scaled to sum to the sample size).

\section{Measures}


Dependent Variables Health is a multi-dimensional concept encompassing physical and psychological health outcomes, such as the diagnosis of various diseases, presence of symptoms, activity limitations, depression and distress, as well as the subjective appraisal of one's own health. In this paper, we provide a comprehensive measure of health by including four measures of health. First, subjective health status, which provides a respondent's global assessment of his/her health, is based on the question. In general, how would you say your health is? and has a five-point scale: poor (coded as 0), fair (1), good (2), very good (3), or excellent (4). Second, respondents were asked if they either do or do not have a long-term chronic health problem (e.g., arthritis, migraine headaches, high blood pressure, heart disease) that has lasted or is expected to last six months or more and that has been diagnosed by a health professional. Third, to measure functional health we use the Health Utility Index (HUI), which combines both qualitative and quantitative aspects of health (i.e., a description and a valuation of health attributes) (Feeny, Furlong, Torrance, Goldsmith, Zhu, Depauw, Denton \& Boyle, 2002). Developed at McMaster University's Centre for Health Economics and Policy Analysis, it provides a measure of overall functional health based on a combination of eight self-reported characteristics of a respondent's health: vision, hearing, speech, mobility, dexterity, cognition, emotion, and pain/discomfort. HUI scores range from about 0.000 to 1.000 (perfect functional health) in increments of 0.001 . Fourth, distress, which is defined as an unpleasant subjective state (Ross \& Van Willigen, 1997), is used as a gauge of mental and emotional well-being. It is based on a subset of items from the Composite International Diagnostic Interview/CIDI. 
Distress is a summative index derived from six items. Specifically, respondents were asked how often, during the month prior to the interview, did they feel: 1) so sad that nothing could cheer you up; 2) nervous; 3) restless/fidgety; 4) hopeless; 5) worthless; and 6) everything was an effort. Responses to each item ranged from none of the time (coded as 0 ) to all of the time (4). Hence, composite scores ranged from 0 to 24 , with higher scores indicating more distress.

Independent Variables Social determinants of health are categorized here into three broad groups: social structural, behavioural, and psycho-social. We also take a multidimensional approach to measuring each of these determinants.

Social structure is measured in five ways. First, age is a categorical variable and it has been recoded to the category midpoint and added as a continuous variable to the analysis. Those 20 years of age and older are the focus of this analysis. Second, family structure has multiple categories, which range from living alone to living with a spouse to living with a parent(s). Third, we gauge social support using a perceived social support index, which comprises four items that reflect whether or not respondents feel that they have someone: they can confide in; they can count on; who can give them advice; and who makes them feel loved. Respondents answered either yes (coded as 1) or no (0) to each item; hence, the overall range of scores is 0 to 4 , and a higher score reflects greater perceived social support. Fourth, we measure activity status by combining the main-activity variable (i.e., what respondents consider to be their current main activity, such as working in the paid labour force, caring for a family, or retired) with the work-activity variable (i.e., 
full-time job [30+ hours per week] or part-time job). Fifth, we use years of education, occupational status, and income adequacy to gauge socio-economic status. Education has 12 categories ranging from no schooling to a medical or graduate degree, but we assign a value indicating total years of schooling to each category. Occupational status is based on the Pineo socio-economic classification of occupations for main job (respondents who did not work in the year prior to the interview are categorized as not applicable) (see Pineo, 1984 for more information). Developed by Statistics Canada, income adequacy has five discrete categories. Respondents are classified as having either low, low-middle, middle, upper-middle, or high income adequacy depending on the dollar-distance between their annual household income and the Canadian low-income cutoff (poverty) lines (see the recent Social Science \& Medicine paper by McDonough, Walters, \& Strohschein (2002) for this exact classification).

A category for missing income values is also created and used in the analysis. While the interpretative value of this category is rather ambiguous, including this large number of missing cases helps to maintain a much fuller (and less biased) sample in the analysis. This method is also employed for any other categorical variable with missing values; missing data in a continuous variable are replaced with the mean score (for the entire sample) of that variable.

Multiple indicators are also used to measure health-related behaviours (i.e., lifestyle). First, physical activity level is based on the amount of energy expended doing different forms of leisure (e.g., exercise/physical) activity. Categories range from active (i.e., 
respondents who expend a minimum of 3.0 calories per kilogram of body weight per day in activity during their leisure time) to moderate ( $1.5-2.9$ calories) and inactive ( $<1.5$ calories). A more detailed explanation of how energy expenditure is calculated is found in the 19941995 NPHS User's Guide (see Statistics Canada, 1995). Second, body weight is measured using the Body Mass Index (BMI). The BMI is calculated by dividing weight in kilograms by height in metres squared. Based on Health Canada guidelines, those with a BMI sore of $<20$ are categorized as having insufficient weight, $20-24$ acceptable weight, 25 to 27 some excess weight, and $>27$ overweight. The final measures of lifestyle are type of smoker and alcohol drinker (i.e., regular/daily, occasional, abstainer) and number of years smoked and number of weekly alcohol drinks consumed.

Multiple indicators are also used to measure psycho-social determinants of health. First we use both the childhood trauma index and the recent life events index that are available in the NPHS. The former index measures the number of traumatic events (e.g., lengthy hospital stay, parental divorce, frequent parental alcohol/drug use) respondents may have been exposed to while they were a child or a teenager, before moving out of the house. The recent life events index is based on the number of negative events which the respondent or someone close to the respondent (i.e., spouse/partner, child, relative, or close friend) experienced in the 12 months prior to the interview, such as physical abuse, major financial crisis, and/or serious problem at work or in school. Higher scores indicate more traumas/events.

Second, chronic stressors that respondents are exposed to in certain domains of 
their lives are gauged. These dimensions of chronic stress include personal problems, financial problems, relationship problems, child (parental) problems, environmental problems, family health problems and job-related problems. We dichotomize each stress index into no stress (coded as 0 ) and stress (1). A detailed description of these indexes is available from the authors.

Third, psychological resources are measured by: a six-item self-esteem index (scores range from 0 to 24), reflecting the amount of positive feelings an individual holds about him/herself; a seven-item mastery index (scores range from 0 to 28), which measures the extent to which an individual believes that his/her life-chances are under his/her control; and a thirteen-item sense of coherence scale that shows the extent to which individuals perceive life events as comprehensible, manageable and meaningful (scores range from 7 to 91 ). Higher scores indicate greater self-esteem, mastery and sense of coherence. It should be noted that while there is a relationship between self-esteem, mastery and coherence to some extent, each factor also has a unique effect on health i.e., the level of collinearity between these variables that exists does not compromise the analyses presented here.

In the end, age, education, social support, years smoked, weekly alcohol consumption and the indexes of childhood/recent trauma, self-esteem, mastery, and coherence are treated as continuous variables in the analyses. All other independent variables are treated as categorical data, and therefore entered in the analysis as sets of dummy variables; the reference category for each set of dummy variables is shown in the 
tables.

\section{Methods of Analysis}

Block-regression coefficients (i.e., $R^{2}$ ) are used to assess the relative contribution of structural, behavioural and psycho-social determinants of health (Table 3). The differential exposure hypothesis is formally tested using Multiple Classification Analysis (MCA) techniques (Table 2). Multiple linear/logit regression techniques are used to test the differential vulnerability hypothesis (Table 4) - i.e., gender differences in the relative importance of each individual structural, behavioural and psycho-social determinant of health is assessed by comparing unstandardized regression coefficients for men and for women (note, we compute interactions between gender and the predictors to determine significant gender differences in these coefficients). . A significance level of $p<.01$ was used to correct for the number of tests conducted.

\section{Limitations}

Certain limitations with the data used here must be acknowledged. First, the NPHS household data file does not cover persons residing in institutions, most of whom are older women. Relatedly, the gender-bias in mortality (i.e., men compared to women at middle ages are more likely to suffer from life-threatening chronic health conditions such as diabetes and heart disease, and therefore have a higher probability of being deceased by older age) may produce a healthier population of elderly men.

Second, NPHS data, like most other health studies and data, are based on subjects' 
responses to health-related questions. It is possible, therefore, that respondents' perceptions of their health differ somewhat from diagnosed health problems among Canadians. It is also possible that observed gender differences in health are to some extent attributable to differential health-reporting behaviours of men and women.

Third, it is difficult to establish causality between social forces and health because of the nature (i.e., cross-sectional) of the data used here. While it is possible that health status shapes social resources to some extent, we presume, based on previous research (e.g., Hirdes \& Forbes,1989; Turner \& Lloyd, 1995; Wheaton, 1994; Wolfson et al., 1993), that social forces have a causal influence on health (we therefore feel confident in describing these social forces as predictors or determinants of health in this paper). For example, Wheaton (1994) has demonstrated that while mental health status can influence subsequent experiences of stressful events, there is a causal link in the opposite direction, from social stress to mental health. As discussed by Turner \& Lloyd (1995) the issue that illness also causes stress exposure does not question the causal status of stress with respect to illness; it simply complicates the proper estimation of this causal impact, and their impact must be controlled either statistically or by design.

The NPHS indeed has a longitudinal component that can be used to explore causality, but many of the social (namely psycho-social) indicators that are central to our analysis are available in the first wave (1994-1995) of the NPHS only. We do plan to conduct a longitudinal analysis as the NPHS datafile matures, especially if psycho-social determinants are included in future surveys. In the end, the 1994-1995 NPHS is the only 
representative, large-scale/national dataset to consider the full complement of structural, behavioural and psycho-social determinants of health, and is the best available Canadian data for this particular study.

\section{RESULTS}

Table 1 presents for males and females separately the means and percentages for the social structural, behavioural and psycho-social determinants of health and Table 2 presents means and percentages for the four measures of health. Previous research has

documented gender differences in health and those results are confirmed here. In particular, women report slightly lower levels of self-rated health, functional health, and higher levels of distress than men. They also report more chronic health problems.

Table 3 shows the relative importance of social structural, behavioural and psychosocial determinants of health for both men and women. Each of these determinants was entered as a block using multiple linear (for self-rated health, HUI and distress) and multiple logistic (for chronic illness) regression analysis techniques. Column 1 shows the proportion of variance explained by all of the structural (S), behavioural $(B)$ and psycho-social $(P)$ variables acting in combination. Together they explain from 17 to $45 \%$ of the variance in self-rated health, HUI, distress and chronic illness. Columns 2-4 show the results of the analyses that entered only structural, behavioural or psycho-social determinants, respectively, in the equation. These analyses demonstrate that for both men and women, structural determinants of health as a group explain the greatest proportion of the variance 
in self-rated, functional and chronic health, while psycho-social determinants as a group are the strongest predictors of distress.

\section{Testing the Differential Exposure Hypothesis}

We argue that women's poorer health is partly due to their reduced access, on average, to the material and social conditions of life that foster health, to their differential exposure to stressful life events and to the everyday stressors associated with women's social roles. However, men's health may also be reduced by their greater likelihood to engage in risk behaviours such as smoking and excessive drinking.

Indeed, we find (see Table 1) that women are generally more likely than men to be: older; living alone or as single parents; in lower income quintiles; carrying a double day (working full or part-time and caring for a family); working in the home caring for a family; and working in lower status occupations; yet, women on average have more social support. Men, on the other hand, are significantly more likely to be regular smokers and drinkers and overweight than women. Important gender differences are also evident in the psychosocial variables, with women reporting more stressful life events and childhood trauma and, with the exception of financial and environment dimensions, more chronic stress in the various domains (i.e., personal, relationship, child and family-health) of life than men; they also report significantly lower levels of self-esteem, mastery and coherence.

While these findings offer indirect support for the differential exposure hypothesis, 
Table 2 formally tests this hypothesis using MCA techniques. In the first analysis, labelled before controls, the various measures of health were regressed on gender. In the second analysis, labelled after controls, measures of health were regressed on gender controlling for social structural, behavioural and psycho-social determinants of health: if gender differences in health are due to the differential exposure of men and women to these factors, we would expect these differences to disappear.

The first three columns of Table 2 present the bivariate relationships between gender and the four measures of health used in this study. The data show that women report significantly lower levels of self-rated health and functional health (HUI) and higher levels of distress compared to men. They are also significantly more likely to report experiencing a chronic condition.. The results in the last three columns, however, show that gender-based inequalities in health remain when controlling for the structural, behavioural and psycho-social determinants of health. Only self-rated health shows no gender differences once social determinants are controlled. Thus we find minimal support for the differential exposure hypothesis. The next section therefore focuses on differential vulnerabilities to these forces between men and women to further help explain the remaining gender differences in $\mathrm{HUI}$, distress and chronic illness.

\section{Testing the Differential Vulnerability Hypothesis}

Now that we have collectively examined the relative importance of structural, behavioural and psycho-social determinants of health, Table 4 elaborates on this analysis 
by showing the relative importance of each individual determinant of health. To assess which structural, behavioural and psycho-social factors are associated with health for men and for women, separate multiple linear (for HUI and distress) and logistic (for chronic illness) regression models of health were computed for men (column labelled Males) and for women (column labelled Females); significant gender differences in the regression coefficients are shown in the column labelled Male-Female Different.

Overall, Table 4 reveals significant gender differences in vulnerability to specific indicators of structural, behavioural and psycho-social forces. However, rather than report the results, factor by factor, for simplicity sake, we will provide an overview of the trends shown in this table.

Looking first at social structural determinants of health, older respondents are more likely than younger ones to report poorer functional health, more chronic illness, but less distress. The relationships for family structure appear to be more important for women (the reference group is couple with children). Results show that unattached female respondents who live alone are more likely to have a chronic health problem while their male counterparts are less likely to experience a chronic illness. Adult children, especially female children, still living with their family of birth, in general, have poorer scores on most measures of health.

The main activity of daily life appears to be an important determinant of health (the reference group here is working full-time). Women who both work outside the home and care for a family (the double day) have less distress and better functional health. By 
contrast, women caring for a family only are more likely to have a chronic illness. Not surprisingly, compared to those who work full-time, individuals recovering from an illness have poorer health on all three measures; however, the relationship is much stronger for women for functional health. Retired men have a higher incidence of chronic illness compared to those who work full-time. Going to school is equally associated with greater odds of chronic illness for men and women.

Of the socio-economic status indicators, occupational class is the most important determinant of health, especially for women. For female respondents, employed professionals and semi-professionals have significantly lower HUI scores and suffer from higher levels of distress (the reference occupation group is semi/unskilled clerical). Additionally, women in either skilled clerical/sales/services or unskilled jobs also have more distress. There are fewer significant differences by occupational class for men: selfemployed professionals are less likely to have a chronic health problem, while supervisors/foremen are more likely to have a chronic health problem.

The final social structural predictor of health, social support, is associated with better functional health for women only. Further, while social support is linked to lower distress for all individuals, this is especially the case for women.

In terms of behavioural determinants of health, we examine the effects of smoking, alcohol consumption, physical activity and weight on health. First, the effects of years of smoking appear much stronger for men than women, with the HUI coefficient being more significant for men. Second, men who drink occasionally or who are former drinkers are 
more likely to have a chronic health problem compared to men who abstain from alcohol (the reference group). Women classified as former drinkers also have poorer functional health. Interestingly, though, women who have a moderate amount of alcohol on a regular basis actually have better functional health. Third, while activity level is an equally important determinant of health for both sexes (i.e., physical activity contributes to better health and inactivity contributes to poorer health on many measures of health), the influence of body weight is more significant for women. Women who are overweight are more likely to have a chronic health problem and women who are underweight have higher levels of distress, compared to women with acceptable weight (reference group).

Turning to psycho-social determinants of health, Table 4 shows the important role that life events, chronic stressors and psychological resources play in determining health for both sexes, but this is especially true for women. First, chronic stressors contribute to health, but appear to play a more important role in predicting health for women than men. Personal stress is associated with more distress and poorer functional health for both men and women, and additionally a greater likelihood of chronic illness for women. Financial stress also leads to a greater likelihood of chronic illness for women only. Conversely, relationship stress is associated with poorer functional health and more distress for men only. On the other hand, child stress leads to lower levels of functional health for women only, but greater odds of having a chronic illness for men only. Environmental stress is also associated with poorer functional health and higher levels of distress for women only. Family health stress contributes to higher levels of distress for men, and lower levels of 
functional health for women. Finally, job strain is interestingly negatively associated with distress for women.

Second, self-esteem, mastery and coherence all contribute importantly to better functional health and lower levels of distress for both men and women. However, there are significant gender differences here, with these resources having a stronger influence on distress for women. Having experienced childhood or recent trauma is an important determinant of poor health on all measures for men than women.

\section{DISCUSSION}

Health is a multi-dimensional concept and studies of the determinants of health are difficult to compare given the various measures used by those working in the field. We have been comprehensive in the measures chosen for analysis by including self-rated health, perhaps the most frequently used measure of health in the social sciences; distress, a common measure of mental health; $\mathrm{HUI}$, a new functional measure of health which provides an overall health score to summarize health capacity on eight different attributes; and a measure of chronic health problems. While the value and significance of the coefficients may differ somewhat depending on the measure of health used, clear themes emerge with respect to the importance of the structural, behavioural and psycho-social determinants of health.

We argued in this paper that health is determined by complex layers of intertwining roots or forces, with behavioural and psycho-social determinants of health growing out of the social context of people's lives. In this way, social structural factors indirectly determine 
health in their pathways through behavioural and psycho-social factors. This perspective helps to illuminate those aspects of social organization that contribute to differential exposure to stressors and to the psychological resources that people use to mobilize against stress or physical health problems.

The importance of the social structural context of people's lives for health is clearly a strong theme to emerge in this research as well as our earlier work (Denton \& Walters, 1999) and the work of others (Blaxter, 1990; Lantz et al., 2001; Walters, McDonough \& Strohschein, 2002). Behavioural determinants play less of a role in predicting health, yet their effects also tend to be mediated by social structure (e.g., those with low income are more likely to smoke, drink excessively and be overweight and inactive). The modest impact of lifestyle factors suggests that while these behaviours are important determinants of health status and play a mediating role in health inequalities, they are clearly overshadowed by the impact of social inequality and psycho-social factors in explaining inequalities in health. Clearly, as Macintyre (1997) argues, health-related behaviours do not explain class differences, but contribute to them, and push the explanatory question back to why health behaviours are patterned by socio-economic status in the first place.

Psycho-social determinants have both direct and mediating effects on health. Health inequalities can be understood as resulting from an accumulating cascade of stressful life experiences from childhood to adulthood that cumulatively leave their imprint on levels of health. The types of stress experienced in life are dependent on one's social location (Pearlin, 1989). For example, persons with lower incomes might be more likely to 
experience financial stress, persons with children are more likely to have stress related to parenting or family health. As the statistical analysis show, controlling for social structural determinants clearly reduces the impact of the psycho-social variables. The impact of stress on health may be moderated by psychological resources, such as self-esteem, mastery or coherence. These in turn may be influenced by the social context of people's lives.

Obviously, the causal pathways to health are complex and we have not tried to unravel them in this analysis. Rather, we argue that structural factors, health behaviours and psycho-social factors are all determinants of health, and to understand the relative contribution of each it is necessary to consider their effects net of the other determinants. However, we do provide evidence that health determinants operate in complex layers of intertwining roots with behavioural and psycho-social factors growing out of the social context of people's lives in terms of gender. That is, our findings show that the pathways through which structural, behavioural and psycho-social forces influence health are different for men and women. The exposure hypothesis proposes that gender-based health inequalities are largely the result of the differing social locations of men and women, their differing life style behaviours and the differing number and levels of chronic stressors and life events experienced by men and women. Nonetheless, gender differences in health are only minimally reduced by controlling for exposure to structural, behavioural and psychosocial forces; significant gender differences remain. The vulnerability hypothesis proposes that women's health differs from men's because they also react in different ways to factors 
that determine health. While we found that there is considerable commonality in the social predictors of health, there are indeed important gender differences. First, age, family structure, main activity, education, income, occupation and social support are important structural determinants of health for both men and women, although their effects differ for men and women. Second, smoking, alcohol consumption and physically activity are more important determinants of health status for men and body weight is more important for women. Third, the impact of childhood/life events, chronic stressors and psychological resources play an important role in determining health, but their effects are generally stronger for women than men.

As noted, the causal pathways are complex and we have not tried to sort them out in this analysis. Now that we have established the importance of considering all three categories as determinants of health, more detailed structural equation modelling of the direct and indirect pathways may indeed be warranted. Longitudinal data will also facilitate the exploration of the causal relationship between social forces and health. We do plan to conduct such analyses when the appropriate data are available. 


\section{REFERENCES}

Antonovsky, A. (1987). Unravelling the mystery of health: How people manage stress and stay well. San Francisco: Jossey-Bass.

Arber, S., \& Cooper, H. (1999). Gender differences in health in later life: the new paradox? Social Science and Medicine 48, 61-76.

Arber, S. (1997). Comparing inequalities in women's and men's health: Britain in the 1990s. Social Science and Medicine 66 (6), 773-787.

Baum, A., \& Grunberg, N.E. (1991). Gender, stress and health. Health Psychology 10 (2), 80-85.

Bird C., \& Rieker P. (1999). Gender matters: An integrated model for understanding men's and women's health. Social Science and Medicine, 48 745-755.

Blaxter M. (1990). Health and Lifestyles. London: Routledge. 
D’Arcy, C. (1998). Social distribution of health among Canadians. In D. Coburn, C.

D'Arcy, \& G. Torrance (Eds.), Health and Canadian Society: Sociological Perspectives (pp.73-101). University of Toronto Press.

Denton, M., \& Walters, V. (1999). Gender differences in structural and behavioural determinants of health: an analysis of the social production of health. Social Science and Medicine 48, 1221-1235.

de Vries, B., \& Watt, D. (1996). A lifetime of events: Age and gender variations in the life story. International Journal of Aging and Human Development 42 (2), 81-102.

Feeny, D., Furlong, W., Torrance, G.W., Goldsmith, C.H., Zhu, Z., DePauw, S., Denton, M., \& Boyle, M. (2002). Multiattribute and Single Attribute Utility Functions for the Health Utilities Index mark 3 System. Medical Care 40, 113-128.

Hirdes J, \& Forbes W. (1989). Estimates of the relative risk of mortality based on the Ontario Longitudinal Study of Aging. Canadian Journal on Aging 8, 222-237.

House, J.S., Landis, K.R., \& Umberson, D. (1994). Social relationships and health. In P. Conrad \& R. Kern (Eds.), The Sociology of Health and IIIness (4th edition) (pp. 83-92). New York: St. Martin's Press. 
Hunt, K., \& Annandale, E. (1999). Relocating gender and morbidity: Examining men's and women's health in contemporary Western societies. Introduction to Special Issue on gender and health. Social Science and Medicine 48,1-5.

Jemmot, J.B., \& Locke, S.E. (1984). Psychological factors, immunologic mediation, and human susceptibility to infectious diseases: How much do we know? Psychological Bulletin 95 (1), 78-108.

Kessler, R. C., \& McLeod, J. D. (1985). Social support and mental health in community samples. In S. Cohen, \& S. L. Syme (Eds.), Social support and health. New York: Academic Press.

Kessler, R.C., \& McLeod, J.D. (1984). Sex differences in vulnerability to life events. American Sociological Review 19, 620-31.

Kessler, R.C., Price, R.H., \& Wortman, C.B. (1985). Social factors in psychopathology: stress, social support and coping processes. Annual Review of Psychology 36, 531-72.

Kivimaki, M. Feldt, T., Vahtera, J., \& Nurmi, K-E. (2000). Sense of coherence and health: evidence from two cross-lagged longitudinal samples. Social Science and Medicine 50, 583-597. 
Lantz, P. M., Lynch, J. W., House, J. S., Lepkowshi, J. M., Mero, R. P., Musick, M. A., \& Williams, D. R. (2001). Socioeconomic disparities $n$ health change in a longitudinal study of US adults: the role of health-risks behaviours. Social Science and Medicine 53, $29-40$.

Marmot, M., Ryff, C.D., Bumpass, L.L., Shipley, M., \& Marks, N.F. (1997). Social inequalities in health: next questions and converging evidence. Social Science and Medicine 44 (6) 901-10.

Macintyre, S. (1997). The Black Report and beyond what are the issues? Social Science and Medicine 44 (6), 723-45.

Macintyre, S., Hunt, K., \& Sweeting, H. (1996). Gender differences in health: are things really as simple as they seem? Social Science and Medicine 42 (4), 617-24.

Matthews, S., Manory, O., \& Power, C. (1999). Social inequalities in health: are there gender differences? Social Science and Medicine 48, 49-60.

McDonough, P., Walters, V., \& Strohschein, L. (2002). Chronic stress and the social patterning of women's health in Canada. Social Science and Medicine 54 (5), 767-82. 
McDonough, P., \& Walters, V. (2001). Gender and health: reassessing patterns and explanations. Social Science and Medicine 52, 547-559.

McDonough, P. (2000). Job Insecurity and Health. International Journal of Health Services 30, 453-476.

Mirowsky, J., \& Ross, C.E. (1989). Social Causes of Psychological Distress. New York: Aldine de Gruyter.

Pearlin, P. (1989). The sociological study of stress. Journal of Health and Social Behaviour 30, 241-256.

Pearlin, L.I., \& Schooler, C. (1978). The structure of coping. Journal of Health and Social Behaviour 19, 2-21.

Pearlin, L.I., Lieberman, M., Menaghan, E., \& Mullan, J. (1981). The stress process. Journal of Health and Social Behaviour 22, 337-56.

Pineo, P.C. (1984). Revisions of the Pineo-Porter-McRoberts socioeconomic classification of occupations for the 1981 Census. McMaster University, Program for 
Quantitative Studies in Economics and Population Research Paper No. 125 Hamilton.

Prus, S. \& Gee, E. (2003). Gender Differences in the Influence of Economic, Lifestyle, and Psycho-social factors on Later-life Health. Canadian Journal of Public Health 94, $306-9 \ldots$

Pugliesi, K. (1995). Work and well-being: Gender differences in psychological consequences of employment. Social Science and Medicine 36, 57-71.

Rosenberg, M., Schooler, C., \& Schoenbach, C. (1989). Self esteem and adolescent problems: Modelling reciprocal effects. American Sociological Review 54 (6), 1004-1018.

Ross, C. E., \& Bird, C. E. (1994). Sex stratification and health lifestyle: Consequences for men's and women's perceived health. Journal of Health and Social Behaviour 35, 161-178.

Ross, C.E., \&Van Willigen, M. (1997). Education and the subjective quality of life. Journal of Health and Social Behaviour 38, 275-97.

Roxburgh, S. (1996). Gender differences in work and well-being: effects of exposure and vulnerability. Journal of Health and Social Behaviour 37, 265-277. 
Shye, D., Mullooly, J.P., Freeborn, D.K., \& Pope, C. (1995). Gender differences in the relationship between social network support and mortality: a longitudinal study. Social Science and Medicine 41 (7), 935-947.

Statistics Canada (1995). NPHS Public Use Microdata Documentation. Ottawa: Statistics Canada, Health Statistics Division.

Turner, J. R., \& Lloyd, D. (1995). Lifetime traumas and mental health: The significance of cumulative adversity. Journal of Health and Social Behaviour 36, 360-376.

Turner, J. R. \& Roszell, P. 1994. Psycho-social resources and the stress process. In W. Avison \& I. Gotlib (Eds.), Stress and mental heath: Contemporary issues and prospects for the future. New York: Plenum Press.

Turner, J.R., \& Avison, W. R. (1987). Gender and depression: Assessing exposure and vulnerability to life events in a chronically strained population. Journal of Nervous and Mental Diseases 77 (8), 443-55.

Townsend, P., Davidson, N., \& Whitehead, M. (1992) Inequalities in health: The Black Report and The Health Divide London: Penguin. 
Umberson, D., Chen, M.D., House, J.S., Hopkins, K., \& Slaten, E. (1996). The effect of social relationships on psychological well-being: are men and women really so different? American Sociological Review 61, 837-57.

Uitenbroek, D. G., Kerekovska, A., \& Festchieva, N. (1996). Health lifestyle behaviour and socio-demographic characteristics. A study of Varna, Glasgow and Edinburgh. Social Science and Medicine 43 (3), 367-377.

Verbrugge, L.M. (1985). Gender and health: An update on hypothesis and evidence. Journal of Health and Social Behaviour 26, 156-182.

Verbrugge L. M. (1989). The twain meet: empirical explanations of sex differences in health and mortality. Journal of Health and Social Behavior 30, 282-304.

Walters, V., McDonough, P., \& Strohschein, L. (2002). The influence of work, household structure, and social, personal and material resources on gender differences in health: an analysis of the 1994 Canadian national population health survey. Social Science and Medicine 54 (5) 677-692.

Walters, V., Lenton, R., \& McKeary, M. (1995). Women's Health in the Context of Women's Lives. Minister of Supply and Services Canada, Ottawa. 
Wheaton, B. (1990). Life transitions, role histories, and mental health. American Sociological Review 55, 209-223.

Wheaton, B. (1994). Sampling the stress universe. In W.R. Avison \& I.H. Gotlib (Eds.), Stress and Mental Health Contemporary Issues and Prospects for the Future (pp 77114). New York: Plenum Press.

Wolfson M, Rowe G, Gentleman J, \& Tomiak M. (1993) Career earnings and death: a longitudinal analysis of older Canadian men. Journals of Gerontology 48, S167-179.

Zuzanek, J. \& Mannell, R. (1998). Life-cycle squeeze, time pressure, daily stress, and leisure participation: A Canadian perspective. Society and Leisure 21 (2) 513-544. 
Table 1: Means and Percentages for Social Structural Measures, by Sex

\begin{tabular}{|c|c|c|}
\hline & Males & Females \\
\hline Age ** & 44.1 & 45.5 \\
\hline $\begin{array}{l}\text { Living Arrangement }{ }^{* *} \\
\text { Unattached \& Alone } \\
\text { Unattached \& Not Alone } \\
\text { Spouse/Partner Only } \\
\text { Couple \& Children } \\
\text { Single Parent w/Children } \\
\text { Child w/Single Parent } \\
\text { Child w/Single Parent \& Siblings } \\
\text { Child w/2 Parents } \\
\text { Child w/2 Parents \& Siblings } \\
\text { Other } \\
\text { Missing }\end{array}$ & $\begin{array}{r}12.5 \% \\
3.8 \\
26.5 \\
38.7 \\
1.6 \\
1.4 \\
0.9 \\
2.7 \\
3.7 \\
7.9 \\
0.3 \\
\end{array}$ & $\begin{array}{r}14.9 \% \\
2.5 \\
24.6 \\
36.1 \\
7.8 \\
0.8 \\
0.6 \\
1.4 \\
2.3 \\
8.7 \\
0.3\end{array}$ \\
\hline $\begin{array}{l}\text { Activity } * * \\
\text { Work FIT \& Care Family } \\
\text { Work PIT \& Care Family } \\
\text { Caring for Family } \\
\text { Work FIT } \\
\text { Work PIT } \\
\text { Going to School } \\
\text { Recover Illness } \\
\text { Retired } \\
\text { Other } \\
\text { Missing } \\
\end{array}$ & $\begin{array}{r}10.8 \% \\
0.5 \\
0.8 \\
61.3 \\
4.4 \\
2.6 \\
2.2 \\
14.9 \\
1.6 \\
--- \\
\end{array}$ & $\begin{array}{r}19.4 \% \\
10.1 \\
19.4 \\
24.9 \\
4.2 \\
2.6 \\
1.9 \\
15.8 \\
1.5 \\
0.03\end{array}$ \\
\hline Education ** & 13.11 & 12.83 \\
\hline $\begin{array}{l}\frac{\text { Income }}{}{ }^{\text {} *} \\
1^{\text {st }} \text { Quintile } \\
2^{\text {nd }} \text { Quintile } \\
3^{\text {rd }} \text { Quintile } \\
4^{\text {th }} \text { Quintile } \\
5^{\text {th }} \text { Quintile } \\
\text { Missing }\end{array}$ & $\begin{array}{r}4.8 \% \\
9.3 \\
26.9 \\
36.8 \\
17.4 \\
4.8\end{array}$ & $\begin{array}{r}6.4 \% \\
13.5 \\
29.2 \\
33.3 \\
13.5 \\
4.2\end{array}$ \\
\hline $\begin{array}{l}\text { Occupation }{ }^{* *} \\
\text { Self-employed Professional } \\
\text { Employed Prof/High Management } \\
\text { Semi-Prof/Technician/Mid Manag. } \\
\text { Supervisor/Foreperson } \\
\text { Skill Clerical/Sales/Service } \\
\text { Skill Crafts/Trades } \\
\text { Semi\&Unskilled Clerical } \\
\text { Farm/Semi\&Unskilled Labourer } \\
\text { Not in Labour Force }\end{array}$ & $\begin{array}{r}1.1 \% \\
8.8 \\
14.2 \\
5.1 \\
2.8 \\
11.0 \\
7.9 \\
24.2 \\
21.6\end{array}$ & $\begin{array}{r}0.4 \% \\
6.7 \\
12.7 \\
1.6 \\
8.5 \\
0.5 \\
19.4 \\
8.4 \\
39.7\end{array}$ \\
\hline
\end{tabular}




\begin{tabular}{||l|r|r||}
\hline Missing & 3.3 & 2.0 \\
\hline Social Support ** & 3.67 & 3.77 \\
\hline
\end{tabular}

Means and Percentages for Behavioural Measures, by Sex

\begin{tabular}{|c|c|c|}
\hline & Males & Females \\
\hline $\begin{array}{l}\frac{\text { Type of Smoker }}{\text { Daily }} \\
\text { Occasional (Former Daily) } \\
\text { Always Occasional } \\
\text { Former Daily } \\
\text { Former Occasional } \\
\text { Never } \\
\text { Missing }\end{array}$ & $\begin{array}{c}28.6 \% \\
3.2 \\
1.6 \\
28.3 \\
7.2 \\
31.0 \\
0.04\end{array}$ & $\begin{array}{c}24.2 \% \\
2.7 \\
1.6 \\
21.1 \\
7.4 \\
43.0 \\
0.01\end{array}$ \\
\hline Years Smoked ** & 13.68 & 9.46 \\
\hline $\begin{array}{l}\text { Type of Alc. Drinker ** } \\
\text { Regular } \\
\text { Occasional } \\
\text { Former } \\
\text { Never } \\
\text { Missing }\end{array}$ & $\begin{array}{r}71.9 \% \\
12.9 \\
10.0 \\
5.0 \\
0.1\end{array}$ & $\begin{array}{r}48.1 \% \\
26.5 \\
14.5 \\
10.9 \\
-----\end{array}$ \\
\hline No. of Alc. Drinks p/w ** & 4.79 & 1.78 \\
\hline $\begin{array}{l}\text { Physical Activity ** } \\
\text { Active } \\
\text { Moderate } \\
\text { Inactive } \\
\text { Missing }\end{array}$ & $\begin{array}{r}19.4 \% \\
22.5 \\
58.1 \\
0.03\end{array}$ & $\begin{array}{r}14.0 \% \\
21.4 \\
64.5 \\
0.1\end{array}$ \\
\hline $\begin{array}{l}\text { Weight }{ }^{* *} \\
\text { Insufficient } \\
\text { Acceptable } \\
\text { Some excess } \\
\text { Over } \\
\text { Missing }\end{array}$ & $\begin{array}{r}3.1 \% \\
33.5 \\
27.5 \\
22.1 \\
13.8\end{array}$ & $\begin{array}{r}10.5 \% \\
38.9 \\
12.9 \\
17.1 \\
20.6\end{array}$ \\
\hline
\end{tabular}

Means and Percentages for Psycho-social Measures, by Sex

\begin{tabular}{||l|r|r||}
\hline & Males & Females \\
\hline Personal stress ** & $56.4 \%$ & $62.2 \%$ \\
\hline Financial stress ** & $39.8 \%$ & $36.3 \%$ \\
\hline Relationship stress ** & $22.6 \%$ & $25.5 \%$ \\
\hline Child stress ** & $22.6 \%$ & $26.3 \%$ \\
\hline Environmental stress & $27.7 \%$ & $26.3 \%$ \\
\hline Family health stress ** & $20.7 \%$ & $24.9 \%$ \\
\hline
\end{tabular}




\begin{tabular}{||l|r|r||}
\hline Job Stress & $69.9 \%$ & $70.6 \%$ \\
\hline Low Stress & 24.4 & 25.5 \\
High Stress & 5.7 & 3.9 \\
Missing & 20.4 & 20.15 \\
\hline Self Esteem Score ** & 19.93 & 19.35 \\
\hline Mastery Score ** & 59.69 & 58.63 \\
\hline Sense of Coherence Score ** & 0.57 & 0.63 \\
\hline Recent Life Events Score ** & 0.78 & 0.93 \\
\hline Child/adulthood Events Score $* *$ & & \\
\hline \hline
\end{tabular}

${ }^{* *}=\mathrm{p} \leq .001$ (statistical significance based on t-test for means and chi-square test for percentages); $n=15,088$.

Table 2: Multiple Classification Analysis of Selected Health Outcomes, before and after Structural, Behavioural, and Psycho-social Controls

\begin{tabular}{||l|c|c|c|c|c|c||}
\hline & \multicolumn{2}{|c|}{ BEFORE CONTROLSBEFORE } & \multicolumn{2}{|c||}{ AFTER CONTROLSAFTER } \\
\hline HEALTH STATUS & Males & Females & $\begin{array}{c}\text { Male- } \\
\text { Female } \\
\text { Different } \\
\text { Different } \\
\text { Different }\end{array}$ & Males & Females & $\begin{array}{c}\text { Male- } \\
\text { Female } \\
\text { Different } \\
\text { Different } \\
\text { Different }\end{array}$ \\
\hline $\begin{array}{l}\text { Self-rated Health } \\
\text { (mean score) }\end{array}$ & 2.78 & 2.69 & $* *$ & 2.73 & 2.74 & \\
\hline $\begin{array}{l}\text { Functional Health (HUI) } \\
\text { (mean score) }\end{array}$ & 0.903 & 0.884 & $* *$ & 0.897 & 0.890 & $*$ \\
\hline $\begin{array}{l}\text { Distress } \\
\text { (mean score) }\end{array}$ & 2.97 & 3.66 & $* *$ & 3.1 & 3.54 & $* *$ \\
\hline $\begin{array}{l}\text { Chronic Condition } \\
\text { (percentage with) }\end{array}$ & 52.7 & 59.8 & $* *$ & 54.1 & 58.6 & $* *$ \\
\hline \hline
\end{tabular}

${ }^{*}=p \leq .01,{ }^{* *}=p \leq .001$ (statistical significance is based on t-test for means and chi-square test for percentages, and is shown in the

"Male-Female Different" column); n= 15,088. 
Table 3: Decomposition of Variance Explained $\left(R^{2}\right)$ of Selected Health Outcomes, by Structural (S), Behavioural (B) and Psycho-social (P) factors and by Sex

\begin{tabular}{||l|l|l|l|l||}
\hline \hline HEALTH STATUS & \multicolumn{1}{|c|}{ ALL } & \multicolumn{1}{c||}{ S } & \multicolumn{1}{c||}{ B } \\
\hline $\begin{array}{l}\text { Self-rated } \\
\text { Men } \\
\text { Women }\end{array}$ & .290 & & & \\
\hline Functional Health (HUI) & & $.189(65.2 \%)^{\mathrm{a}}$ & $.140(48.3 \%)$ & $.120(41.4 \%)$ \\
\hline $\begin{array}{l}\text { Men } \\
\text { Women }\end{array}$ & .308 & $.188(61.0)$ & $.108(35.1)$ & $.156(50.7)$ \\
\hline $\begin{array}{l}\text { Distress } \\
\text { Men }\end{array}$ & .364 & $.198(64.1)$ & $.083(26.9)$ & $.151(48.9)$ \\
Women & $.380(63.2)$ & $.080(22.0)$ & $.199(54.7)$ \\
\hline Chronic Condition & .446 & $.095(24.5)$ & $.042(10.8)$ & $.368(94.9)$ \\
\hline $\begin{array}{l}\text { Men } \\
\text { Women }\end{array}$ & .174 & $.133(29.8)$ & $.041(9.2)$ & $.418(93.7)$ \\
\hline
\end{tabular}

a. Component $R^{2}$ as a percentage of total $R^{2} ; \mathrm{n}=15,088$ 
Table 4: Unstandardized OLS Regression Coefficients for HUI and Distress and Logistic Regression Odd Ratios for Chronic Condition on Structural, Behavioural, and Psycho-social Factors, by Sex

Structural Factors

\begin{tabular}{|c|c|c|c|c|c|c|c|c|c|}
\hline & Males & Females & $\begin{array}{c}\text { Male- } \\
\text { Female } \\
\text { Different } \\
\text { Different } \\
\text { Different }\end{array}$ & Males & Females & $\begin{array}{c}\text { Male- } \\
\text { Female } \\
\text { Different }\end{array}$ & Males & Females & $\begin{array}{c}\text { Male- } \\
\text { Female } \\
\text { Different }\end{array}$ \\
\hline & \multicolumn{2}{|c|}{ HUI } & & \multicolumn{2}{|c|}{ Distress } & & \multicolumn{2}{|c|}{ Chronic Condition } & \\
\hline Age & $-0.001^{* *}$ & $-0.002^{\star *}$ & & $-0.017^{* *}$ & $-0.011^{*}$ & & $1.02^{\star *}$ & $1.03^{* *}$ & \\
\hline $\begin{array}{l}\text { Living Arrangement } \\
\text { Unattached \& Alone } \\
\text { Unattached \& Not Alone } \\
\text { Spouse/Partner Only } \\
\text { Couple \& Children (ref) } \\
\text { Single Parent w/Children } \\
\text { Child w/Single Parent } \\
\text { Child w/Single Parent \& Siblings } \\
\text { Child w/2 Parents } \\
\text { Child w/2 Parents \& Siblings } \\
\text { Other } \\
\text { Missing }\end{array}$ & $\begin{array}{r}-0.001 \\
0.002 \\
-0.007 \\
\\
-0.010 \\
-0.004 \\
0.011 \\
-0.010 \\
0.001 \\
0.007 \\
-0.020 \\
\end{array}$ & $\begin{array}{r}0.004 \\
-0.001 \\
-0.004 \\
\\
-0.004 \\
0.001 \\
0.006 \\
-0.016 \\
-0.017 \\
-0.013^{*} \\
0.042 \\
\end{array}$ & * & $\begin{array}{r}0.03 \\
0.16 \\
0.16 \\
\\
0.07 \\
-0.09 \\
0.53 \\
0.11 \\
0.26 \\
-0.30^{*} \\
-0.71 \\
\end{array}$ & $\begin{array}{r}0.09 \\
-0.09 \\
0.20 \\
\\
0.19 \\
0.25 \\
-0.96 \\
0.22 \\
0.71^{*} \\
0.36^{*} \\
-0.45 \\
\end{array}$ & * & $\begin{array}{l}0.80 \\
0.79 \\
1.06 \\
\\
0.67 \\
0.72 \\
0.58 \\
0.74 \\
0.86 \\
0.74 \\
2.36\end{array}$ & $\begin{array}{l}1.25^{\star} \\
1.23 \\
1.10 \\
1.12 \\
1.98^{*} \\
1.07 \\
2.08^{\star *} \\
0.75 \\
0.85 \\
0.17^{\star *}\end{array}$ & $\begin{array}{l}\text { ** } \\
* \\
* * \\
* *\end{array}$ \\
\hline $\begin{array}{l}\text { Activity } \\
\text { Work FIT \& Care Family } \\
\text { Work PIT \& Care Family } \\
\text { Caring for Family } \\
\text { Work F/T (ref) } \\
\text { Work PIT } \\
\text { Going to School } \\
\text { Recover Illness } \\
\text { Retired } \\
\text { Other } \\
\text { Missing } \\
\end{array}$ & $\begin{array}{r}0.003 \\
-0.012 \\
-0.043 \\
-0.001 \\
0.004 \\
-0.197^{\star *} \\
-0.012 \\
-0.001 \\
---- \\
\end{array}$ & $\begin{array}{r}0.013^{\star *} \\
0.010 \\
-0.012 \\
\\
-0.005 \\
-0.014 \\
-0.267^{\star *} \\
-0.034 \\
0.014 \\
0.013 \\
\end{array}$ & * & $\begin{array}{r}-0.24 \\
-0.21 \\
0.87 \\
\\
-0.32 \\
0.68^{* *} \\
0.60 \\
0.26 \\
0.08 \\
----- \\
\end{array}$ & $\begin{array}{r}-0.41^{* *} \\
-0.29 \\
-0.62 \\
\\
-0.18 \\
0.56 \\
1.32^{*} \\
-0.48 \\
-0.67 \\
-0.21 \\
\end{array}$ & * & $\begin{array}{l}0.99 \\
1.11 \\
1.59 \\
\\
1.12 \\
2.05^{\star} \\
24.05^{\star \star} \\
5.10^{\star \star} \\
3.70^{\star \star} \\
-\cdot-- \\
\end{array}$ & $\begin{array}{l}0.97 \\
1.04 \\
2.17^{*} \\
\\
1.33 \\
2.09^{\star *} \\
14.44^{\star *} \\
3.36^{\star \star} \\
1.30 \\
0.01\end{array}$ & \\
\hline Education & 0.001 & 0.001 & & 0.03 & 0.02 & & 1.01 & 1.03 & \\
\hline $\begin{array}{l}\frac{\text { Income }}{1^{\text {st }} \text { Quintile }} \\
2^{\text {nd }} \text { Quintile } \\
3^{\text {rd }} \text { Quintile (ref) } \\
4^{\text {th }} \text { Quintile } \\
5^{\text {th }} \text { Quintile } \\
\text { Missing }\end{array}$ & $\begin{array}{r}-0.006 \\
-0.007 \\
\\
-0.007 \\
-0.002 \\
0.004\end{array}$ & $\begin{array}{r}0.003 \\
-0.003 \\
\\
0.001 \\
0.006 \\
-0.007\end{array}$ & & $\begin{array}{r}0.19 \\
0.14 \\
\\
-0.11 \\
-0.02 \\
-0.42^{\star *}\end{array}$ & $\begin{array}{r}-0.05 \\
0.25 \\
\\
-0.14 \\
-0.20 \\
-0.06\end{array}$ & & $\begin{array}{l}1.07 \\
1.08 \\
\\
1.13 \\
1.50^{\star \star} \\
1.25\end{array}$ & $\begin{array}{l}0.83 \\
0.84 \\
\\
1.06 \\
1.11 \\
0.84\end{array}$ & \\
\hline
\end{tabular}

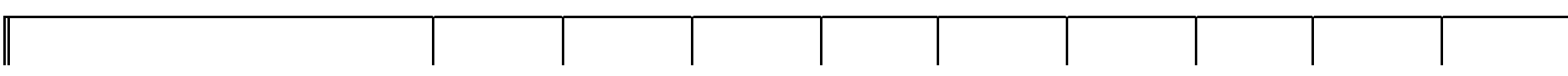




\begin{tabular}{|c|c|c|c|c|c|c|c|}
\hline $\begin{array}{l}\text { Occupation } \\
\text { Self-employed Professional } \\
\text { Employed Prof/High Management } \\
\text { Semi-Prof/Technician/Mid Manag. } \\
\text { Supervisor/Foreperson } \\
\text { Skill Clerical/Sales/Service Skill } \\
\text { Crafts/Trades } \\
\text { Semi\&Unskilled Clerical (ref) } \\
\text { Farm/Semi\&Unskilled Labourer } \\
\text { Not in Labour Force } \\
\text { Missing }\end{array}$ & $\begin{array}{r}0.003 \\
-0.007 \\
-0.008 \\
-0.001 \\
0.007 \\
-0.004-0 . \\
001 \\
-0.028 \\
-0.010\end{array}$ & $\begin{array}{r}-0.005 \\
-0.016^{*} \\
-0.019^{* *} \\
-0.004 \\
-0.009 \\
-0.023-0 . \\
002 \\
-0.010 \\
0.001\end{array}$ & $\begin{array}{r}-0.64 \\
0.02 \\
0.15 \\
-0.11 \\
0.41 \\
-0.23-0 . \\
07 \\
0.07 \\
-0.24\end{array}$ & $\begin{array}{r}0.38 \\
0.39^{\star} \\
0.32^{\star} \\
-0.42 \\
0.31^{\star} \\
0.06 \\
0.54^{\star *} \\
0.80 \\
0.25\end{array}$ & ** & $\begin{array}{l}0.53^{\star} \\
1.13 \\
1.21 \\
1.47^{\star} \\
0.98 \\
0.89 \\
1.13 \\
0.36^{\star *} \\
0.91\end{array}$ & $\begin{array}{l}1.58 \\
1.48^{\star *} \\
1.17 \\
1.10 \\
1.07 \\
0.900 .91 \\
0.63 \\
0.84\end{array}$ \\
\hline Social Support & 0.001 & $0.006^{*}$ & $-0.12^{*}$ & $-0.30^{\star *}$ & * & 1.08 & 1.04 \\
\hline
\end{tabular}

Behavioural Factors

\begin{tabular}{|c|c|c|c|c|c|c|c|c|}
\hline $\begin{array}{l}\frac{\text { Type of Smoker }}{\text { Daily }} \\
\text { Occasional (Former Daily) } \\
\text { Always Occasional } \\
\text { Former Daily } \\
\text { Former Occasional } \\
\text { Never (ref) } \\
\text { Missing }\end{array}$ & $\begin{array}{r}0.008 \\
-0.033^{* *} \\
-0.008 \\
0.003 \\
-0.009 \\
0.162\end{array}$ & $\begin{array}{r}0.013^{*} \\
0.011 \\
0.006 \\
0.005 \\
0.001 \\
0.036\end{array}$ & $* *$ & $\begin{array}{r}0.20 \\
0.53^{*} \\
0.35 \\
0.07 \\
0.25 \\
\\
-0.62\end{array}$ & $\begin{array}{r}0.11 \\
0.34 \\
0.84^{\star *} \\
-0.10 \\
0.10 \\
-2.76\end{array}$ & $\begin{array}{l}0.75^{\star} \\
1.02 \\
0.68 \\
1.06 \\
1.00 \\
11.2\end{array}$ & $\begin{array}{l}1.07 \\
0.81 \\
1.02 \\
1.16 \\
1.13 \\
\\
37.25\end{array}$ & * \\
\hline Years Smoked & $-0.001^{\star *}$ & $-0.001^{*}$ & & 0.00 & 0.01 & 1.01 & 1.00 & \\
\hline $\begin{array}{l}\text { Type of Alc. Drinker } \\
\text { Regular } \\
\text { Occasional } \\
\text { Former } \\
\text { Never (ref) } \\
\text { Missing }\end{array}$ & $\begin{array}{r}0.012 \\
0.004 \\
-0.005 \\
0.009 \\
\end{array}$ & $\begin{array}{r}0.013^{\star *} \\
0.004 \\
-0.015^{\star} \\
-0.001 \\
\end{array}$ & & $\begin{array}{r}-0.16 \\
-0.14 \\
0.12 \\
-0.29\end{array}$ & $\begin{array}{l}-0.11 \\
-0.00 \\
-0.15 \\
-----\end{array}$ & $\begin{array}{l}1.35 \\
1.45^{\star} \\
1.89^{\star \star} \\
4.60\end{array}$ & $\begin{array}{l}0.94 \\
1.04 \\
1.21 \\
-----\end{array}$ & * \\
\hline \# of Alc. drinks p/w & -0.001 & 0.001 & & 0.00 & 0.02 & 1.00 & 1.00 & \\
\hline $\begin{array}{l}\text { Physical Activity } \\
\text { Active } \\
\text { Moderate (ref) } \\
\text { Inactive } \\
\text { Missing }\end{array}$ & $\begin{array}{r}0.002 \\
-0.009 * \\
0.027\end{array}$ & $\begin{array}{r}0.013^{*} \\
-0.006^{*} \\
0.046\end{array}$ & & $\begin{array}{r}-0.13 \\
\\
0.16 \\
-0.00\end{array}$ & $\begin{array}{r}-0.03 \\
0.29 * * \\
0.64 \\
\end{array}$ & $\begin{array}{l}0.81^{*} \\
0.87 \\
0.23\end{array}$ & $\begin{array}{l}1.10 \\
1.06 \\
19.38\end{array}$ & * \\
\hline $\begin{array}{l}\text { Weight } \\
\text { Insufficient } \\
\text { Acceptable (ref) } \\
\text { Some excess } \\
\text { Over } \\
\text { Missing }\end{array}$ & $\begin{array}{r}-0.008 \\
0.001 \\
-0.004 \\
-0.001\end{array}$ & $\begin{array}{l}0.001 \\
-0.003 \\
-0.004 \\
-0.012\end{array}$ & & $\begin{array}{l}0.37 \\
-0.13 \\
-0.09 \\
-0.18\end{array}$ & $\begin{array}{r}0.30^{*} \\
0.05 \\
-0.01 \\
0.26^{*}\end{array}$ & $\begin{array}{l}1.19 \\
1.05 \\
1.05 \\
1.09 \\
1.15\end{array}$ & $\begin{array}{l}0.95 \\
1.12 \\
1.54^{\star *} \\
1.42^{\star *}\end{array}$ & ** \\
\hline \multicolumn{9}{|l|}{ Psycho-social Factors } \\
\hline Personal stress & $-0.011^{* *}$ & $-0.01^{*}$ & & $0.63^{* *}$ & $0.58^{\star *}$ & 1.04 & $1.42^{\star *}$ & ** \\
\hline Financial stress & 0.003 & -0.01 & & -0.02 & -0.04 & 1.105 & $1.22^{\star *}$ & \\
\hline
\end{tabular}




\begin{tabular}{|c|c|c|c|c|c|c|c|c|}
\hline Relationship stress & $-0.008^{*}$ & -0.004 & $0.22^{*}$ & 0.19 & & 1.14 & 0.91 & * \\
\hline Child stress & 0.001 & $-0.009 *$ & 0.09 & 0.07 & & $1.32^{\star *}$ & 1.17 & \\
\hline Environmental stress & -0.004 & $-0.009^{* *}$ & 0.07 & $0.32^{* *}$ & & 1.06 & 1.09 & \\
\hline Family health stress & -0.002 & $-0.010^{\star *}$ & $0.27^{\star \star}$ & 0.04 & * & 1.14 & 1.10 & \\
\hline $\begin{array}{l}\frac{\text { Job }}{\text { Low Stress }} \\
\text { Missing } \\
\text { High Stress }\end{array}$ & $\begin{array}{l}-0.010 \\
-0.001\end{array}$ & $\begin{array}{l}-0.013 \\
-0.001\end{array}$ & $\begin{array}{r}0.57^{* *} \\
-0.11\end{array}$ & $\begin{array}{r}0.41^{*} \\
-0.40^{* *}\end{array}$ & * & $\begin{array}{l}1.00 \\
1.04\end{array}$ & $\begin{array}{l}0.70^{\star *} \\
0.98\end{array}$ & \\
\hline Self Esteem & $0.003^{* *}$ & $0.004^{\star *}$ & $-0.04^{*}$ & $-0.08^{* *}$ & * & 0.99 & 0.99 & \\
\hline Mastery & $0.001^{* *}$ & $0.003^{\star *}$ & $-0.09 * *$ & $-0.11^{\star \star}$ & & 1.00 & $0.97^{*}$ & \\
\hline Coherence & $0.002^{\star *}$ & $0.002^{\star *}$ & $-0.11^{\star *}$ & $-0.12^{\star \star}$ & * & $0.99^{*}$ & 1.00 & \\
\hline Child/adulthood Events & $-0.008^{\star *}$ & $-0.008^{\star \star}$ & $0.16^{* *}$ & $0.14^{* *}$ & & $1.17^{* *}$ & $1.26^{\star *}$ & \\
\hline $\begin{array}{l}\text { Recent Life EventsRecent Life } \\
\text { EventsRecent Life Events }\end{array}$ & $-0.006^{\star *}$ & -0.002 & $0.25^{\star *}$ & $0.23^{* *}$ & & $1.19^{\star *}$ & $1.15^{\star *}$ & \\
\hline
\end{tabular}

${ }^{*}=p \leq .01,{ }^{* *}=p \leq .001$ (note, statistically significant interactions between gender and the predictors are shown in the

"Male-Female Different" column); $n=15,088$ 